\title{
Correction: Fixed point theorems of contractive mappings in cone $b$-metric spaces and applications
}

Huaping Huang ${ }^{1}$ and Shaoyuan $\mathrm{Xu}^{2^{*}}$

\section{*Correspondence:}

xushaoyuan@126.com

${ }^{2}$ Department of Mathematics and

Statistics, Hanshan Normal

University, Chaozhou, 521041, China

Full list of author information is

available at the end of the article

\section{Correction}

In this note we correct some errors that appeared in the article (Huang and $\mathrm{Xu}$ in Fixed Point Theory Appl. 2013:112, 2013) by modifying some conditions in the main theorems and examples.

After examining the proofs of the main results in [1], we can find that there is something wrong with the proof of the Cauchy sequence in [1, Theorem 2.1]. This leads to subsequent errors in Theorem 2.3 and related examples in [1]. We also find that it is not rigorous to use the corresponding lemmas, and so the proof is inaccurate. The detailed reasons are given in the following.

On p.5 in [1], we conclude that

$$
\frac{s^{p} \lambda^{m+1}}{s-\lambda} d\left(x_{1}, x_{0}\right)+s^{p-1} \lambda^{m} d\left(x_{1}, x_{0}\right) \rightarrow \theta
$$

as $m \rightarrow \infty$ for any $p \geq 1$. This is incorrect. Indeed, note that taking $\lambda=\frac{1}{\sqrt{s}}>\frac{1}{s}$ and $p=m+1$ leads to

$$
\frac{s^{p} \lambda^{m+1}}{s-\lambda} d\left(x_{1}, x_{0}\right)+s^{p-1} \lambda^{m} d\left(x_{1}, x_{0}\right)=\frac{s^{\frac{m+2}{2}}}{s^{\frac{3}{2}}-1} d\left(x_{1}, x_{0}\right)+s^{\frac{m}{2}} d\left(x_{1}, x_{0}\right) \nrightarrow \theta
$$

as $m \rightarrow \infty$. Therefore, it is impossible to utilize [1, Lemma 1.8, 1.9] and demonstrate that $\left\{x_{n}\right\}$ is a Cauchy sequence.

In this note, we would like to slightly modify only one of the used conditions to achieve our claim.

The following theorem is a modification to [1, Theorem 2.1]. The proof is the same as that in [1] except the proof of the Cauchy sequence. We will attain the desired goal by using the new modified condition $\lambda \in\left[0, \frac{1}{s}\right)$ instead of $\lambda \in[0,1)$.

Theorem 2.1 Let $(X, d)$ be a complete cone b-metric space with the coefficient $s \geq 1$. Suppose that the mapping $T: X \rightarrow X$ satisfies the contractive condition

$$
d(T x, T y) \leq \lambda d(x, y) \quad \text { for } x, y \in X
$$


where $\lambda \in\left[0, \frac{1}{s}\right)$ is a constant. Then $T$ has a unique fixed point in X. Furthermore, the iterative sequence $\left\{T^{n} x\right\}$ converges to the fixed point.

Proof In order to show that $\left\{x_{n}\right\}$ is a Cauchy sequence, we only need the following calculations. For any $m \geq 1, p \geq 1$, it follows that

$$
\begin{aligned}
d\left(x_{m}, x_{m+p}\right) \leq & s\left[d\left(x_{m}, x_{m+1}\right)+d\left(x_{m+1}, x_{m+p}\right)\right] \\
\leq & s d\left(x_{m}, x_{m+1}\right)+s^{2}\left[d\left(x_{m+1}, x_{m+2}\right)+d\left(x_{m+2}, x_{m+p}\right)\right] \\
\leq & s d\left(x_{m}, x_{m+1}\right)+s^{2} d\left(x_{m+1}, x_{m+2}\right)+s^{3} d\left(x_{m+2}, x_{m+3}\right) \\
& +\cdots+s^{p-1} d\left(x_{m+p-2}, x_{m+p-1}\right)+s^{p-1} d\left(x_{m+p-1}, x_{m+p}\right) \\
\leq & s \lambda^{m} d\left(x_{1}, x_{0}\right)+s^{2} \lambda^{m+1} d\left(x_{1}, x_{0}\right)+s^{3} \lambda^{m+2} d\left(x_{1}, x_{0}\right) \\
& +\cdots+s^{p-1} \lambda^{m+p-2} d\left(x_{1}, x_{0}\right)+s^{p} \lambda^{m+p-1} d\left(x_{1}, x_{0}\right) \\
= & s \lambda^{m}\left[1+s \lambda+s^{2} \lambda^{2}+\cdots+(s \lambda)^{p-1}\right] d\left(x_{1}, x_{0}\right) \leq \frac{s \lambda^{m}}{1-s \lambda} d\left(x_{1}, x_{0}\right) .
\end{aligned}
$$

Let $\theta \ll c$ be given. Notice that $\frac{s \lambda^{m}}{1-s \lambda} d\left(x_{1}, x_{0}\right) \rightarrow \theta$ as $m \rightarrow \infty$ for any $p$. Making full use of [1, Lemma 1.8], we find $m_{0} \in \mathbb{N}$ such that

$$
\frac{s \lambda^{m}}{1-s \lambda} d\left(x_{1}, x_{0}\right) \ll c
$$

for each $m>m_{0}$. Thus,

$$
d\left(x_{m}, x_{m+p}\right) \leq \frac{s \lambda^{m}}{1-s \lambda} d\left(x_{1}, x_{0}\right) \ll c
$$

for all $m \geq 1, p \geq 1$. So, by [1, Lemma 1.9], $\left\{x_{n}\right\}$ is a Cauchy sequence in $(X, d)$. The proof is completed.

As is indicated in the reviewer's comments, [1, Example 2.2] is too trivial. Therefore, [1, Example 2.2] is withdrawn. Now we give another example as follows.

Example 2.2 Let $X=[0,0.48], E=\mathbb{R}^{2}$ and let $1 \leq p \leq 6$ be a constant. Take $P=\{(x, y) \in$ $E: x, y \geq 0\}$. We define $d: X \times X \rightarrow E$ as

$$
d(x, y)=\left(|x-y|^{p},|x-y|^{p}\right) \quad \text { for all } x, y \in X .
$$

Then $(X, d)$ is a complete cone $b$-metric space with $s=2^{p-1}$. Let us define $T: X \rightarrow X$ as

$$
T x=\frac{1}{2}\left(\cos \frac{x}{2}-\left|x-\frac{1}{2}\right|\right) \quad \text { for all } x \in X \text {. }
$$

Thus, for all $x, y \in X$, we have

$$
\begin{aligned}
d(T x, T y) & =\left(|T x-T y|^{p},|T x-T y|^{p}\right) \\
& =\frac{1}{2^{p}}\left(\left|\left(\cos \frac{x}{2}-\cos \frac{y}{2}\right)-\left(\left|x-\frac{1}{2}\right|-\left|y-\frac{1}{2}\right|\right)\right|^{p},\right.
\end{aligned}
$$




$$
\begin{aligned}
& \left.\left|\left(\cos \frac{x}{2}-\cos \frac{y}{2}\right)-\left(\left|x-\frac{1}{2}\right|-\left|y-\frac{1}{2}\right|\right)\right|^{p}\right) \\
\leq & \frac{1}{2^{p}}\left(\left(\left|\cos \frac{x}{2}-\cos \frac{y}{2}\right|+|x-y|\right)^{p},\left(\left|\cos \frac{x}{2}-\cos \frac{y}{2}\right|+|x-y|\right)^{p}\right) \\
\leq & \frac{1}{2^{p}}\left(\left(\frac{|x+y|}{8}|x-y|+|x-y|\right)^{p},\left(\frac{|x+y|}{8}|x-y|+|x-y|\right)^{p}\right) \\
\leq & 0.56^{p}\left(|x-y|^{p},|x-y|^{p}\right)<\frac{1}{2^{p-1}}\left(|x-y|^{p},|x-y|^{p}\right) .
\end{aligned}
$$

Hence, by Theorem 2.1, there exists $x_{0} \in X$ (in fact, it satisfies $0.472251591454<x_{0}<$ 0.472251591479 ) such that $x_{0}$ is the unique fixed point of $T$.

For the same reason, we need to use the new condition $\lambda_{1}+\lambda_{2}+s\left(\lambda_{3}+\lambda_{4}\right)<\frac{2}{1+s}$ instead of the original condition $\lambda_{1}+\lambda_{2}+s\left(\lambda_{3}+\lambda_{4}\right)<\min \left\{1, \frac{2}{s}\right\}$ in [1, Theorem 2.3]. The correct statement is as follows.

Theorem 2.3 Let $(X, d)$ be a complete cone $b$-metric space with the coefficient $s \geq 1$. Suppose that the mapping $T: X \rightarrow X$ satisfies the contractive condition

$$
d(T x, T y) \leq \lambda_{1} d(x, T x)+\lambda_{2} d(y, T y)+\lambda_{3} d(x, T y)+\lambda_{4} d(y, T x) \quad \text { for } x, y \in X
$$

where the constant $\lambda_{i} \in[0,1)$ and $\lambda_{1}+\lambda_{2}+s\left(\lambda_{3}+\lambda_{4}\right)<\frac{2}{1+s}, i=1,2,3,4$. Then T has a unique fixed point in $X$. Moreover, the iterative sequence $\left\{T^{n} x\right\}$ converges to the fixed point.

Proof Following an identical argument that is given in [1, Theorem 2.3] except substituting $0 \leq \lambda \leq 1$ for $0 \leq \lambda \leq \frac{1}{s}$ in line 26 of p.6 in [1], we obtain the proof of Theorem 2.3.

In addition, based on the changes of Theorem 2.1, we need to change the condition $h^{2}<$ $\min \left\{\frac{\delta}{M^{2}}, \frac{1}{L^{2}}\right\}$ into $h^{2}<\min \left\{\frac{\delta}{M^{2}}, \frac{1}{2 L^{2}}\right\}$ for [1, Example 3.1]. Let us give the corrected example.

We now apply Theorem 2.1 to the first-order periodic boundary problem

$$
\left\{\begin{array}{l}
\frac{\mathrm{d} x}{\mathrm{~d} t}=F(t, x(t)), \\
x(0)=\xi
\end{array}\right.
$$

where $F:[-h, h] \times[\xi-\delta, \xi+\delta]$ is a continuous function.

Example 2.4 Consider boundary problem (2.1) with the continuous function $F$, and suppose that $F(x, y)$ satisfies the local Lipschitz condition, i.e., if $|x| \leq h, y_{1}, y_{2} \in[\xi-\delta$, $\xi+\delta]$, it induces

$$
\left|F\left(x, y_{1}\right)-F\left(x, y_{2}\right)\right| \leq L\left|y_{1}-y_{2}\right|
$$

Set $M=\max _{[-h, h] \times[\xi-\delta, \xi+\delta]}|F(x, y)|$ such that $h^{2}<\min \left\{\frac{\delta}{M^{2}}, \frac{1}{2 L^{2}}\right\}$, then there exists a unique solution of (2.1).

Proof Let $X=E=C([-h, h])$ and $P=\{u \in E: u \geq 0\}$. Put $d: X \times X \rightarrow E$ as $d(x, y)=$ $f(t) \max _{-h \leq t \leq h}|x(t)-y(t)|^{2}$ with $f:[-h, h] \rightarrow \mathbb{R}$ such that $f(t)=e^{t}$. It is clear that $(X, d)$ is a complete cone $b$-metric space with $s=2$. 
Note that (2.1) is equivalent to the integral equation

$$
x(t)=\xi+\int_{0}^{t} F(\tau, x(\tau)) \mathrm{d} \tau
$$

Define a mapping $T: C([-h, h]) \rightarrow \mathbb{R}$ by $T x(t)=\xi+\int_{0}^{t} F(\tau, x(\tau)) \mathrm{d} \tau$. If

$$
x(t), y(t) \in B(\xi, \delta f) \triangleq\{\varphi(t) \in C([-h, h]): d(\xi, \varphi) \leq \delta f\},
$$

then from

$$
\begin{aligned}
d(T x, T y) & =f(t) \max _{-h \leq t \leq h}\left|\int_{0}^{t} F(\tau, x(\tau)) \mathrm{d} \tau-\int_{0}^{t} F(\tau, y(\tau)) \mathrm{d} \tau\right|^{2} \\
& =f(t) \max _{-h \leq t \leq h}\left|\int_{0}^{t}[F(\tau, x(\tau))-F(\tau, y(\tau))] \mathrm{d} \tau\right|^{2} \\
& \leq h^{2} f(t) \max _{-h \leq \tau \leq h}|F(\tau, x(\tau))-F(\tau, y(\tau))|^{2} \\
& \leq h^{2} L^{2} f(t) \max _{-h \leq \tau \leq h}|x(\tau)-y(\tau)|^{2} \\
& =h^{2} L^{2} d(x, y),
\end{aligned}
$$

and

$$
d(T x, \xi)=f(t) \max _{-h \leq t \leq h}\left|\int_{0}^{t} F(\tau, x(\tau)) \mathrm{d} \tau\right|^{2} \leq h^{2} f \max _{-h \leq \tau \leq h}|F(\tau, x(\tau))|^{2} \leq h^{2} M^{2} f \leq \delta f,
$$

we speculate that $T: B(\xi, \delta f) \rightarrow B(\xi, \delta f)$ is a contractive mapping.

Finally, we prove that $(B(\xi, \delta f), d)$ is complete. In fact, suppose that $\left\{x_{n}\right\}$ is a Cauchy sequence in $B(\xi, \delta f)$. Then $\left\{x_{n}\right\}$ is also a Cauchy sequence in $X$. Since $(X, d)$ is complete, there is $x \in X$ such that $x_{n} \rightarrow x(n \rightarrow \infty)$. So, for each $c \in \operatorname{int} P$, there exists $N$, whenever $n>N$, we obtain $d\left(x_{n}, x\right) \ll c$. Thus, it follows from

$$
d(\xi, x) \leq d\left(x_{n}, \xi\right)+d\left(x_{n}, x\right) \leq \delta f+c
$$

and Lemma 1.12 in [1] that $d(\xi, x) \leq \delta f$, which means $x \in B(\xi, \delta f)$, that is, $(B(\xi, \delta f), d)$ is complete.

Owing to the above statement, all conditions of Theorem 2.1 are satisfied. Hence $T$ has a unique fixed point $x(t) \in B(\xi, \delta f)$. That is to say, there exists a unique solution of (2.1).

Remark 2.5 Theorem 2.1 and Theorem 2.3 generalize and improve the corresponding results in $[2-4]$. 


\section{Acknowledgements}

The authors thank the referees, the editors and the readers including Prof. Sriram Balasubramanian and Prof. Reny George Special thanks are due to Prof. Ravi P. Agarwal and Prof. Ljubomir Ciric, who have made a number of valuable comments and suggestions, which have improved [1] greatly. The research is partially supported by the PhD Start-up Fund of Hanshan Normal University, Guangdong Province, China (No. QD20110920).

Received: 26 November 2013 Accepted: 26 November 2013 Published: 5March 2014

\section{References}

1. Huang, $\mathrm{H}, \mathrm{Xu}, \mathrm{S}$ : Fixed point theorems of contractive mappings in cone $b$-metric spaces and applications. Fixed Point Theory Appl. 2013, 112 (2013)

2. Jovanović, M, Kadelburg, Z, Radenović, S: Common fixed point results in metric-type spaces. Fixed Point Theory Appl. 2010, Article ID 978121 (2010). doi:10.1155/2010/97812

3. Khamsi, MA: Remarks on cone metric spaces and fixed point theorems of contractive mappings. Fixed Point Theory Appl. 2010, Article ID 315398 (2010). doi:10.1155/2010/315398

4. Shah, MH, Smić, S, Hussain, N, Sretenović, A, Radenović, S: Common fixed points theorems for occasionally weakly compatible pairs on cone metric type spaces for b-metric spaces. J. Comput. Anal. Appl. 14(2), 290-297 (2012)

doi:10.1186/1687-1812-2014-55

Cite this article as: Huang and $\mathrm{Xu}$ : Correction: Fixed point theorems of contractive mappings in cone $b$-metric spaces and applications. Fixed Point Theory and Applications 2014 2014:55.

\section{Submit your manuscript to a SpringerOpen ${ }^{\odot}$ journal and benefit from:}

- Convenient online submission

Rigorous peer review

Immediate publication on acceptance

- Open access: articles freely available online

- High visibility within the field

- Retaining the copyright to your article 